\title{
Cu-Catalyzed three-component coupling reactions using nitriles, 1,3-dienes and silylboranes
}

$\operatorname{AUTHOR}(S)$ :

Matsuda, Yuki; Tsuji, Yasushi; Fujihara, Tetsuaki

\section{CITATION:}

Matsuda, Yuki ... [et al]. Cu-Catalyzed three-component coupling reactions using nitriles, 1,3-dienes and silylboranes. Chemical Communications 2020, 56(34): 4648-4651

ISSUE DATE:

2020-04-30

URL:

http://hdl.handle.net/2433/261185

\section{RIGHT:}

This is the accepted manuscript of the article, which has been published in final form at

https://doi.org/10.1039/d0cc01803a.; The full-text file will be made open to the public on 1 April 2021 in accordance with publisher's 'Terms and Conditions for Self-Archiving'.; This is not the published version. Please cite only the published version.; この論文は出版社版でありません。引用の際には出版社版をご確認ざ利用ください。 


\title{
Cu-catalyzed three-component coupling reactions using nitriles, 1,3- dienes and silylboranes
}

\author{
Yuki Matsuda, Yasushi Tsuji and Tetsuaki Fujihara*
}

Received 00th January 20xx,

Accepted 00th January 20xx

DOI: $10.1039 / \times 0 \times x 00000 x$

This paper reports novel $\mathrm{Cu}$-catalyzed three-component coupling reactions using nitriles, 1,3-dienes and silylboranes. The desired reactions proceed at room temperature and yield $\beta, \gamma$-unsaturated ketones with a (dimethylphenylsilyl)methyl moiety at the $\alpha$ position. Diverse nitriles participate in the reaction and the corresponding products were obtained in good to high yields with high regioselectivity.

The catalytic generation of functionalized nucleophiles followed by trapping with carbon electrophiles is a capable methodology for preparing complex molecules via a carbon-carbon (C-C) bond forming reaction. Conjugated dienes such as 1,2 -dienes ${ }^{1}$ and 1,3dienes $^{2}$ are valuable reaction platforms owing to their diverse array of products. Silyl functionalities are highly useful in organic synthesis and achieve a variety of efficient transformations. ${ }^{3}$ Recently, Cucatalyzed silylative transformation of 1,2-dienes has been invesitgated. ${ }^{4} \mathrm{We}^{5}$ and other groups ${ }^{6,7}$ found the Cu-catalyzed silylative allylation of carbon electrophiles such as carbon dioxide $\left(\mathrm{CO}_{2}\right),{ }^{5 a}$ formates, ${ }^{5 b}$ aldehydes, ${ }^{5 c}$ ketones, ${ }^{5 c, 6}$ and imines ${ }^{7}$ (Scheme 1a). A key to the transformation is the regioselective addition of silyl copper species $^{8}$ to 1,2-dienes, yielding $\beta$-silyl allyl copper intermediates. Addition of copper species to 1,3-dienes is also a method, generating functionalized allyl copper intimidates. Actually, Cu-catalyzed functionalization of 1,3-dienes have been recently reported. ${ }^{9-11}$ However, the control of regioselectivity remains challenging task when simple monosubstituted 1,3-dienes such as isoprene are used as substrates. ${ }^{10 c, e, f}$

Nitrile is a fundamental organic molecule in organic synthesis. ${ }^{12}$ The alkylation of aliphatic nitriles at the $\alpha$-position is an important methodology for constructing a new $\mathrm{C}-\mathrm{C}$ bond. ${ }^{13}$ In addition, nucleophilic addition at the carbon atom in $\mathrm{CN}$ group is also known as a protocol that yields functionalized imines and ketones via a C-C bond formation. ${ }^{14}$ However, in general, the stoichiometric amount of

Department of Energy and Hydrocarbon Chemistry, Graduate School of Engineering, Kyoto University, Kyoto 615-8510, Japan. E-mail: tfuji@scl.kyoto-u.ac.jp FAX: +8175-383-2514

† Footnotes relating to the title and/or authors should appear here.

Electronic Supplementary Information (ESI) available: [details of any supplementary information available should be included here]. See DOI: 10.1039/x0xx00000x strong nucleophiles such as Grignard reagents are necessary owing to their stability. ${ }^{14}$ Although catalytic acylation using nitriles has been reported, ${ }^{15}$ there are several limitations such as intramolecular reactions, ${ }^{15 b . d}$ or harsh reaction conditions. ${ }^{15 c, e}$ Therefore, the catalytic addition of functionalized nucleophiles to nitriles that yields functionalized imines and ketones remains challenging. In this context, very recently, Hoveyda group has reported Cu-catalyzed enantioselective coupling reactions using 1,2-diene, diborone, and nitriles. ${ }^{16}$

Herein we report on catalytic three-component coupling reactions using nitriles, 1,3-dienes, and silylboranes in the presence of copper catalysts (Scheme $1 \mathrm{~b}$ ). The desired reactions proceed at room temperature, and $\beta, \gamma$-unsaturated ketones with a (dimethylphenylsilyl)methyl moiety at the $\alpha$-position are obtained in good to high yields with high regioselectivity after acidic work-up.

First, the reaction of benzonitrile (1a), 2,3-dimethyl-1,3butadiene (2a), and $\mathrm{PhMe}_{2} \mathrm{Si}-\mathrm{B}(\mathrm{pin})$ was conducted by employing $4.0 \mathrm{~mol} \%$ of CuOAc and $10 \mathrm{~mol} \%$ of a ligand in toluene at room temperature (Table 1). ${ }^{17}$ Employing $\mathrm{PPh}_{3}$, the reaction proceeded and $\beta, \gamma$-unsaturated ketones with a (dimethylphenylsilyl)methyl moiety at the $\alpha$-position (3a) was obtained in $88 \%$ yield after acidic work-up (entry 1 ).

Scheme 1 Three-component coupling reactions using conjugated dienes, silylboranes and electrophiles.

(a) Reactions using 1,2-dienes

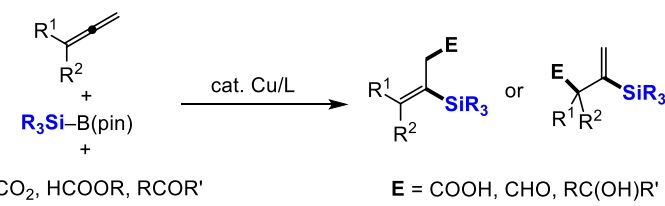

(b) Reactions using 1,3-dienes (This Work)

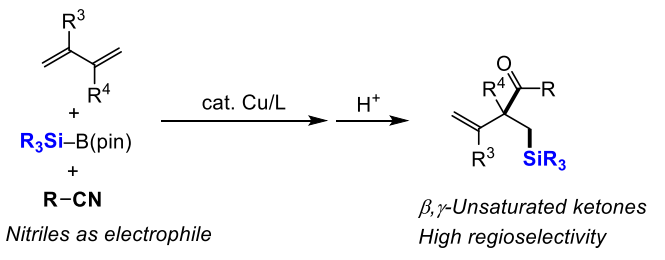


Table 1 Ligand effect on the Cu-catalyzed three-component coupling using benzonitrile (1a), 2,3-dimethyl-1,3-butadiene (2a) and a silylborane ${ }^{a}$

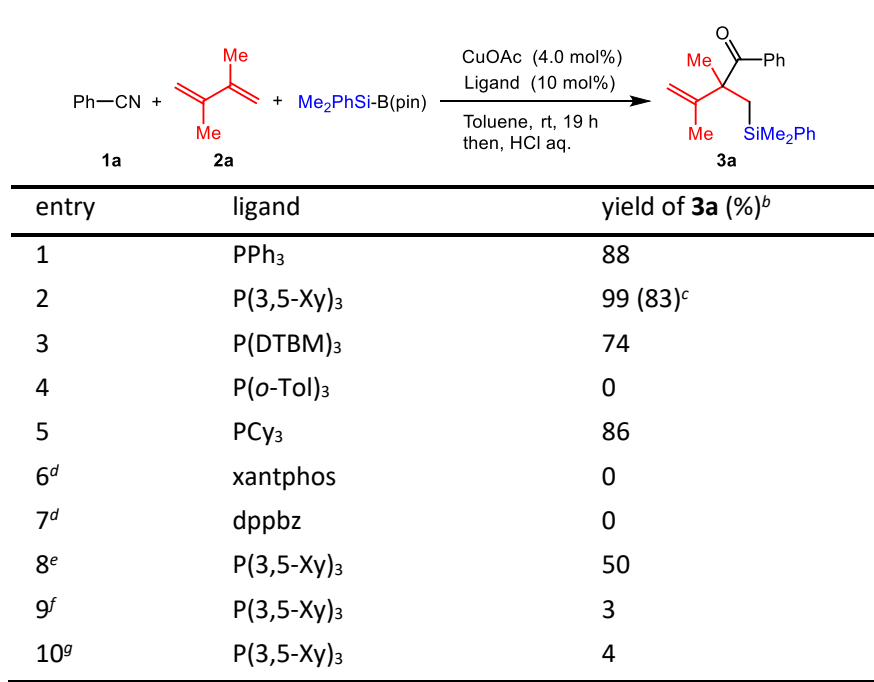

${ }^{a}$ Reaction conditions: benzonitrile (1a, $0.40 \mathrm{mmol}$ ), 2,3-dimethyl-1,3-butadiene ( $2 \mathrm{a}, 0.52 \mathrm{mmol}, 1.3$ equiv), $\mathrm{PhMe}_{2} \mathrm{Si}-\mathrm{B}(\mathrm{pin})$ ( $0.52 \mathrm{mmol}, 1.3$ equiv), CuOAc (4.0 $\mathrm{mol} \%)$, ligand $(10 \mathrm{~mol} \%)$ in toluene $(1.0 \mathrm{~mL})$ at room temperature for $19 \mathrm{~h}$, then $\mathrm{HCl}$ aq. was added. ${ }^{b}$ Determined by GC and GC-MS analysis. ${ }^{c}$ Isolated yield of $3 a$ $d 5.0 \mathrm{mmol}$ of ligand was used. ${ }^{e}$ PhCOF was used in place of $1 \mathrm{a} .{ }^{f}(\mathrm{PhCO})_{2} \mathrm{O}$ was used in place of 1a. ${ }^{g} \mathrm{PhCO}_{2} \mathrm{Me}$ was used in place of $1 \mathrm{a}$.

Under the reaction conditions, no isomer was detected by analyzing crude reaction mixture using GC-MS and NMR measurements. Tri(3,5-xylyl)phosphine $\left(\mathrm{P}(3,5-\mathrm{XY})_{3}\right)$ resulted in the highest yield, giving $3 a$ in $99 \%$ GC yield (entry 2 ). From the reaction mixture, pure 3a was successfully isolated in $83 \%$ yield. The use of more bulky tris(3,5-di-tert-butyl-4methoxyphenyl)phosphine $\left(\mathrm{P}(\mathrm{DTBM})_{3}\right)$ slightly decreased the yield of $\mathbf{3 a}$ (entry 3 ). The reaction using a sterically hindered $\mathrm{P}(\mathrm{O}$ $\mathrm{Tol}_{3}$ did not afford $\mathbf{3 a}$ at all (entry 4). Employing $\mathrm{PCy}_{3}$, 3a was also obtained in high yield (entry 5). On the other hand, bidentate phosphine ligands such as xantphos and dppbz were not efficient (entries 6 and 7). These phosphines would prevent the coordination of 1,3-diene to $\mathrm{Cu}$ center. For catalytic acylation reactions, Riant $^{18}$ and our group ${ }^{19}$ used acid fluorides and acid anhydrides, respectively, in the Cu-catalyzed boraacylation of 1,2-dienes. When these reagents were tested instead of 1a, 3a was obtained in $50 \%$ and $3 \%$ yields, respectively (entries 8 and 9). In the latter case, an acylsilane that was formed by the reaction of silylcopper with benzoic anhydride was detected. Esters such as methyl benzoate were not suitable acylation reagents (entry 10). The present procedure using $\mathrm{P}(3,5-\mathrm{Xy})_{3}$ as the ligand was amenable to a gram-scale reaction. Thus, starting from $0.83 \mathrm{~g}(6.0 \mathrm{mmol})$ of $1 \mathrm{a}$, $1.66 \mathrm{~g}$ of $3 \mathrm{a}$ was obtained in $86 \%$ isolated yield.

Using $\mathbf{2 a}$, various nitriles were employed as substrates under the optimal reaction conditions (Table 2). Aromatic nitriles bearing an electron-donating (1b and $\mathbf{1 c}$ ) or an electronwithdrawing (1d, $\mathbf{1 e}$ and $\mathbf{1 f}$ ) group were converted to the corresponding products in good to high yields with perfect

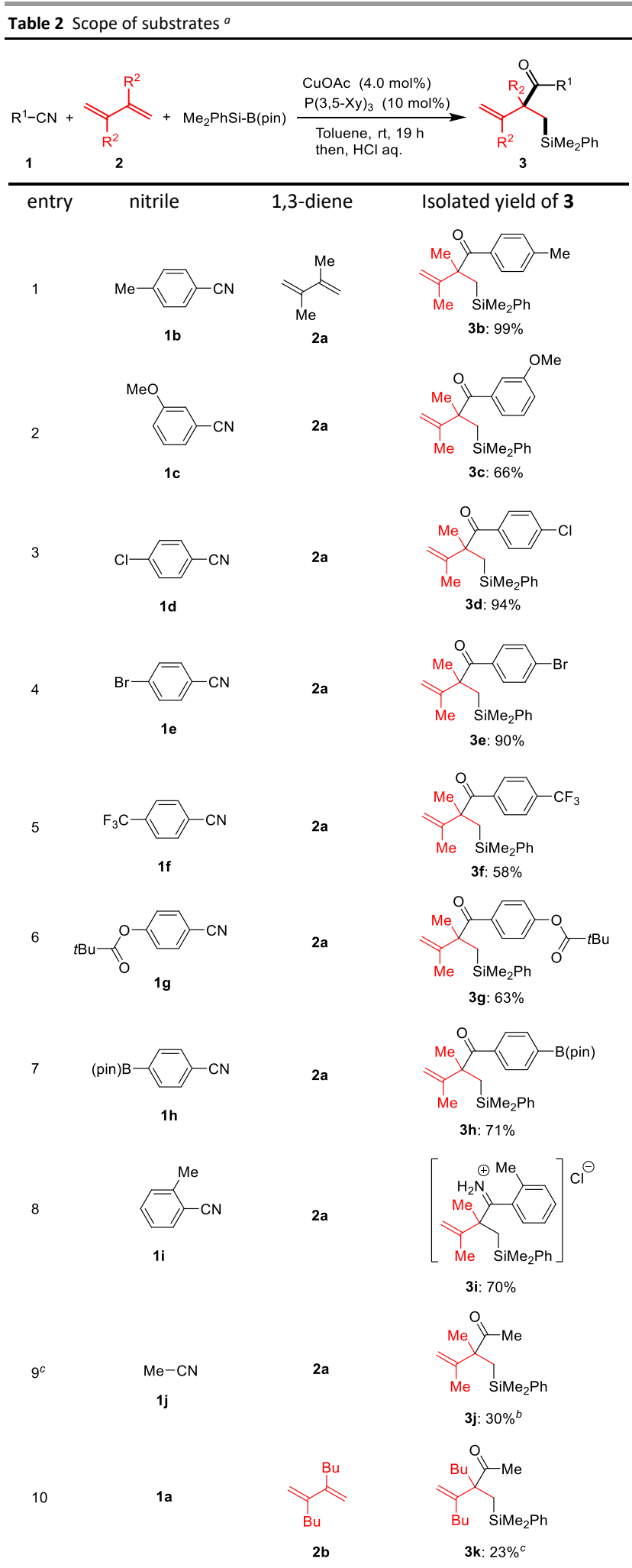

a Reaction conditions: 1 (0.40 mmol), 2 (0.80 mmol, 2.0 equiv), $\mathrm{PhMe}_{2} \mathrm{Si}-\mathrm{B}$ (pin) (0.60 mmol, 1.5 equiv), CuOAc ( $4.0 \mathrm{~mol} \%), \mathrm{P}(3,5-\mathrm{Xy})_{3}(10 \mathrm{~mol} \%)$ in toluene $(1.0$ $\mathrm{mL}$ ) at room temperature for $19 \mathrm{~h}$, then $\mathrm{HCl}$ aq. was added. Isolated yields of 3 were shown. ${ }^{b} \mathrm{PCy}_{3}(10 \mathrm{~mol} \%)$ was used as the ligand. ${ }^{c}$ Determined by GC and GCMS analysis. 
Table 3 Ligand effect on the Cu-catalyzed three-component coupling of 1a, isoprene (2c) and a silylborane ${ }^{a}$

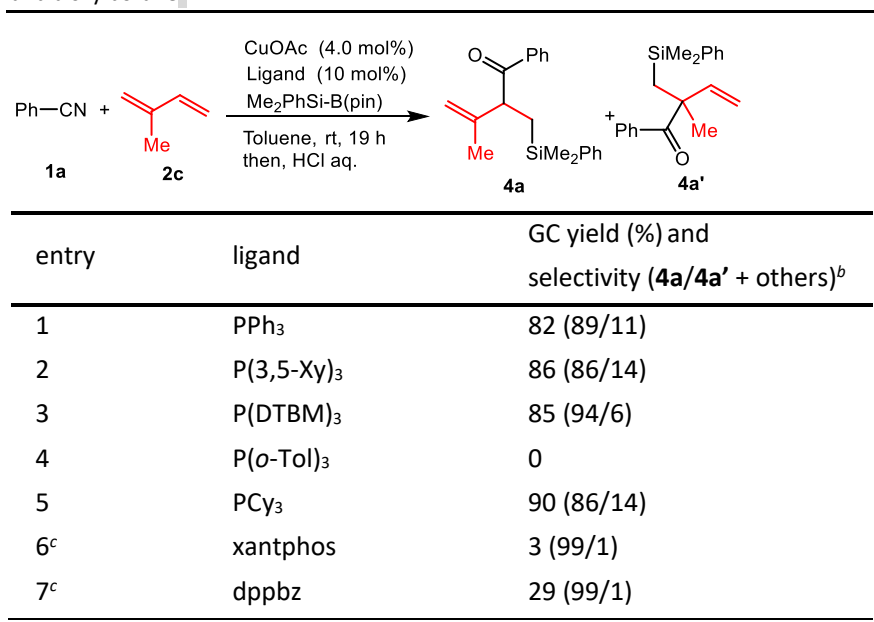

a Reaction conditions: benzonitrile (1a, $0.40 \mathrm{mmol}$ ), 2,3-dimethyl-1,3-butadiene (2a, $0.52 \mathrm{mmol}, 1.3$ equiv), $\mathrm{PhMe}_{2} \mathrm{Si}-\mathrm{B}(\mathrm{pin})$ ( $0.52 \mathrm{mmol}, 1.3$ equiv), CuOAc ( 4.0 $\mathrm{mol} \%)$, ligand $(10 \mathrm{~mol} \%)$ in toluene $(1.0 \mathrm{~mL})$ at room temperature for $19 \mathrm{~h}$, then $\mathrm{HCl}$ aq. was added. ${ }^{b}$ Determined by GC and GC-MS analysis. ${ }^{c} 5.0 \mathrm{mmol}$ of ligand was used.

regioselectivity (entries $1-5)$. Several functional groups such as $\mathrm{Br}-\mathrm{C}\left(\mathrm{sp}^{2}\right)$ (1) $)$, ester (1g), and $\mathrm{B}(\mathrm{pin})(\mathbf{1} \mathbf{h})$ moieties were tolerated in the reaction (entries 4,6 and 7 ). When the reaction of $o$-tolunitrile (1i) with 2 a was carried out, an unexpectedly stable iminium salt (3i) was precipitated during the acidification of the reaction mixture (entry 8 ). Acetonitrile (1j) could participate in the reaction and the corresponding product $\mathbf{3 j}$ was obtained using $\mathrm{PC}_{3}$ as the ligand (entry 9). However, other aliphatic nitriles such as valeronitrile afforded the corresponding products in low yields. Regarding other 2,3disubstituted 1,3-butadienes, 2,3-dibutyl-1,3-butadiene was not a suitable substrate and the corresponding product (3k) was obtained in low yield (entry 10).

Next, the reaction of $1 \mathrm{a}$, isoprene (2c), and $\mathrm{PhMe}_{2} \mathrm{Si}-\mathrm{B}(\mathrm{pin})$ was conducted by employing $4.0 \mathrm{~mol} \%$ of $\mathrm{CuOAc}$ and $10 \mathrm{~mol} \%$ of a ligand in toluene at room temperature (Table 3). ${ }^{17}$ Using $\mathrm{PPh}_{3}$, a mixture of regioisomers was obtained in $82 \%$ total yield with good selectivity $\left(4 a / 4 a^{\prime}\right.$ and others $\left.=89 / 11\right)$, after acidic work-up (entry 1$)$. In the reaction, a product (4a) functionalized at the less hindered carboncarbon double bond in $\mathbf{2 c}$ was obtained as a major isomer. $\mathrm{P}(3,5-\mathrm{Xy})_{3}$ showed a similar efficiency compared to $\mathrm{PPh}_{3}$ (entry 2). In contrast, $\mathrm{P}(\mathrm{DTBM})_{3}$ resulted in the highest selectivity ( $85 \%$ yield, $\left.94 / 6\right)$ (entry 3 ), while $\mathrm{P}(\mathrm{o}-\mathrm{Tol})_{3}$ did not produce $4 \mathrm{a}$ at all (entry 4). The use of $\mathrm{PCy}_{3}$ gave $4 a$ in high yield, but selectivity was not enough (entry 5). As the case using $2 \mathbf{a}$, bidentate phosphines were not good ligands in the reaction (entries 6 and 7).

Using $\mathrm{P}(\mathrm{DTBM})_{3}$ as the ligand, various aromatic nitriles provided $\beta, \gamma$-unsaturated ketones with a (dimethylphenylsilyl)methyl moiety at the $\alpha$-position in good to high isolated yields with high regioselectivity (Table 4, entries 1-6). Several functional groups such as $\mathrm{Cl}-\mathrm{C}\left(\mathrm{sp}^{2}\right)(\mathbf{4 d}), \mathrm{Br}-\mathrm{C}\left(\mathrm{sp}^{2}\right)(\mathbf{4 e})$, ester $(\mathbf{4 g})$, and $\mathrm{B}(\mathrm{pin})(\mathbf{4 h})$ groups were tolerated in the reaction. For 1,3-dienes, myrcene (2d) was subjected to the reaction and the corresponding product (4I) was

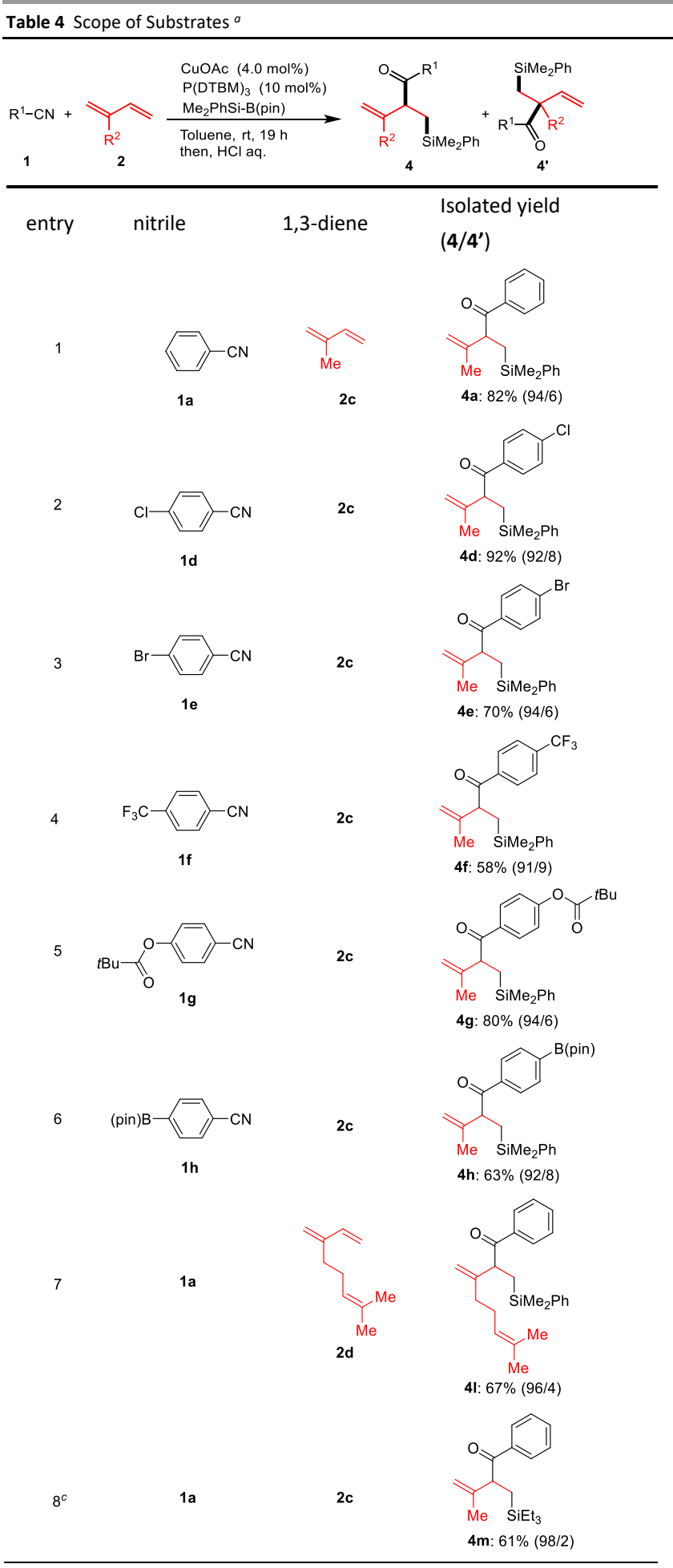

${ }^{a}$ Reaction conditions: nitrile (1, $\left.0.40 \mathrm{mmol}\right), 1,3$-dienes (2, $0.80 \mathrm{mmol}, 2.0$ equiv), $\mathrm{PhMe}_{2} \mathrm{Si}-\mathrm{B}$ (pin) ( $0.60 \mathrm{mmol}, 1.5$ equiv), CuOAc $(4.0 \mathrm{~mol} \%)$, ligand $(10 \mathrm{~mol} \%)$ in toluene $(1.0 \mathrm{~mL})$ at room temperature for $19 \mathrm{~h}$, then $\mathrm{HCl}$ aq. was added. $b$ Determined by GC and GC-MS. ${ }^{c} \mathrm{Et}_{3} \mathrm{Si}-\mathrm{B}$ (pin) in place of $\mathrm{PhMe}_{2} \mathrm{Si}-\mathrm{B}$ (pin) was used.

obtained in good yield (entry 6). Regarding 2-subsituted 1,3butadienes, 2-phenyl-1,3-butadiene did not afford the corresponding product at all. The reaction using $\mathrm{Et}_{3} \mathrm{Si}-\mathrm{B}(\mathrm{pin})$ instead of $\mathrm{PhMe}_{2} \mathrm{Si}-\mathrm{B}$ (pin) afforded a triethylsilyl-substituted product $(\mathbf{4 m})$ in moderate yield (entry 8). 
Scheme 2 shows a plausible reaction mechanism. It is known that silyl copper species (A) is generated upon the reaction of $\mathrm{PhMe}_{2} \mathrm{Si}-$ $\mathrm{B}$ (pin) with copper complexes. ${ }^{8}$ Thus, $\mathbf{A}$ is the key catalyst species involved in the catalytic cycles (step 0 ). Then, $\mathbf{A}$ is subsequently added across a sterically less hindered $\mathrm{C}-\mathrm{C}$ double bond of 1,3-diene (2), yielding an allylcopper intermediates B or B' (step 1). Next, B' would react with a nitrile (1) at the $\gamma$-position to provide $\mathbf{C}$ via 6 membered ring transition state (step 2 ), as proposed in the allylation of nitriles. ${ }^{14}$ Donating ability of monodentate phosphines facilitates the nucleophilic attack step. Finally, the $\sigma$-bond metathesis of $\mathbf{C}$ with $\mathrm{PhMe}_{2} \mathrm{Si}-\mathrm{B}($ pin) produces an imine (D) and regenerates the active catalyst species A (step 4). Acidic work-up provides the corresponding ketone (3).

\section{Scheme 2 Possible Catalytic Cycle}

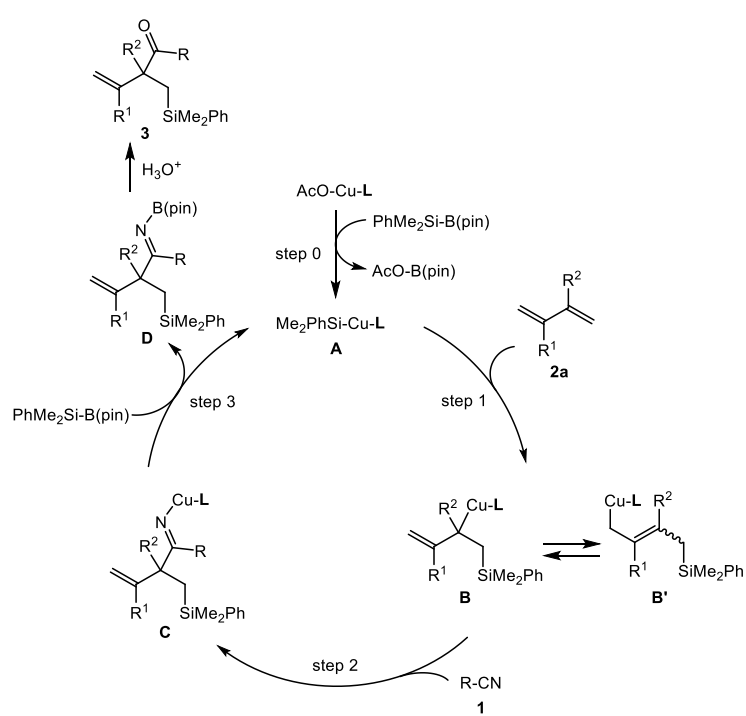

In conclusion, three-component coupling reactions using nitriles, 1,3-dienes, and silylboranes were reported for the first time. The desires reactions proceeded smoothly in the presence of copper catalysts. The corresponding $\beta, \gamma$-unsaturated ketones with a (dimethylphenylsilyl)methyl moiety at the $\alpha$-position were obtained in good to high yields with high regioselectivity. Further studies to clarify reaction mechanism and application to enantioselective reactions are now in progress.

This work was supported by JSPS KAKENHI Grant Number 17 H03096 in Grant-in-Aid for Scientific Research (B) from MEXT, Japan (YT). TF acknowledged JSPS KAKENHI Grant Number $18 \mathrm{H} 04257$ in Precisely Designed Catalysts with Customized Scaffolding from MEXT, Japan and Tokuyama Science Foundation for financial support.

\section{Conflicts of interest}

There are no conflicts to declare.

\section{Notes and references}

1 (a) Modern Allene Chemistry, N. Krause and A. S. K. Hashmi, Eds. Wiley-VCH, Weinheim, 2004. (b) S. Ma, Chem. Rev., 2005, 105, 28292871. (c) M. Jeganmohan and C.-H. Cheng, Chem. Commun., 2008 3101-3117. (d) S. Yu and S. Ma, Angew. Chem. Int. Ed., 2012, 51 3074-3112.

2 (a) N. Herrmann, D. Vogelsang, A. Behr and T. Seidensticker, Chem CatChem, 2018, 10, 5342-5365. (b) Y. Xiong, Y. Sun and G. Zhang Tetrahedron Lett., 2018, 59, 347-355.

3 (a) E. W. Colvin, in Silicon in Organic Synthesis, Butterworths, London, 1981, pp 44-82. (b) E. W. Colvin, in Silicon Reagents in Organic Synthesis, Academic, London, 1988, pp 7-19. (c) E. Langkopf and D. Schinzer, Chem. Rev., 1995, 95, 1375-1408. (d) T. A. Blumenkopf and L. E. Overman, Chem. Rev., 1986, 86, 857-873. (e) I. Fleming, J. Dunogues and R. Smithers, Org. React., 1989, 37, 57-575.

4 T. Fujihara and Y. Tsuji, Synthesis, 2018, 50, 1737-1749.

5 (a) Y. Tani, T. Fujihara, J. Terao and Y. Tsuji, J. Am. Chem. Soc., 2014, 136, 2332-2333. (b) T. Fujihara, A. Sawada, T. Yamaguchi, Y. Tani, J. Terao and Y. Tsuji, Angew. Chem. Int. Ed., 2017, 56, 1539-1543. (c) Y. Tani, T. Yamaguchi, T. Fujihara, J. Terao and Y. Tsuji, Chem. Lett., 2015, 44, 271-273.

6 Z.-T. He, X.-Q. Tang, L.-B. Xie, M. Chen, P. Tian and G.-Q. Lin, Angew. Chem. Int. Ed., 2015, 54, 14815-14818.

7 J. Rae, K. Yeung, J. J. W. McDouall and D. J. Procter, Angew. Chem. Int. Ed., 2016, 55, 1102-1107.

8 C. Kleeberg, M. S. Cheung, Z. Lin and T. B. Marder, J. Am. Chem. Soc., 2011, 133, 19060-190603.

9 G. J. P. Perry, T. Jia and D. J. Procter, ACS Catal., 2020, 10, 1485-1499, and references sited therein.

10 (a) J.-J. Feng and M. Oestreich, Angew. Chem. Int. Ed. 2019, 58, 8211-8215. (b) T. Jia, M. J. Smith, A. P. Pulis, G. J. Perry and D. J. Procter, ACS Catal., 2019, 9, 6744-6750. (c) T. Jia, Q. He, R. E. Ruscoe, A. Pulis and D. J. Procter, Angew. Chem. Int. Ed., 2018, 57, 1130511309. (d) K. B. Smith and M. K. Brown, J. Am. Chem. Soc., 2017, 139, 7721-7724. (e) S. R. Sardini and M. K. Brown, J. Am. Chem. Soc., 2017, 139, 9823-9826. (f) Y. Huang, K. B. Smith and M. K. Brown, Angew. Chem. Int. Ed., 2017, 56, 13314-13318. (g) L. Jiang, P. Cao, M. Wang, B. Chen, B. Wang and J. Liao, Angew. Chem. Int. Ed., 2016, 55, 1385413858. (h) X. Li, F. Meng, S. Torker, Y. Shi and A. H. Hoveyda, Angew. Chem. Int. Ed., 2016, 55, 9997-10002. (i) K. Kubota, Y. Watanabe, K. Hayama and H. Ito, J. Am. Chem. Soc., 2016, 138, 4338-4341. (j) K. Semba, M. Shinomiya, T. Fujihara, J. Terao and Y. Tsuji, Chem. Eur. J., 2013, 19, 7125-7133. (k) Y. Sasaki, C. Zhong, M. Sawamura and H. Ito, J. Am. Chem. Soc., 2010, 132, 1226-1227.

11 (a) X.- W. Chen, L. Zhu, Y.-Y. Gui, K. Jing, Y.-X. Jiang, Z.-Y. Bo, Y. Lan, J. $\mathrm{Li}$ and D.-G. Yu, J. Am. Chem. Soc., 2019, 141, 18825-18835. (b) C. Li, K. Shin, R. Y. Liu and S. L. Buchwald, Angew. Chem. Int. Ed., 2019, 58, 17074-17080. (c) C. Li, R. Y. Liu, L. T. Jesikiewicz, Y. Yang, P. Liu, and S. L. Buchwald, J. Am. Chem. Soc., 2019, 141, 5062-5070. (d) B. Fu, X. Yuan, Y. Li, Y. Wang, Q. Zhang, T. Xiong and Q. Zhang, Org. Lett., 2019, 21, 3576-3580. (e) D. Li, Y. Park, W. Yoon, H. Yun and J. Yun, Org. Lett., 2019, 21, 9699-9703. (f) Y.-Y. Gui, N. Hu, X.-W. Chen, L. Liao, T. Ju, J.H. Ye, Z. Zhang, J. Li and D.-G. Yu, J. Am. Chem. Soc., 2017, 139, 17011-17014.

12 R. C. Larock, Comprehensive Organic Transformation, 2nd Ed., WileyVCH, New York, 1999.

13 (a) A. Cope, H. Holmes and O. House, Org. React., 1957, 9, 107-331. (b) S. Arseniyadis, K. S. Kyler and D. S. Watt, Org. React., 1984, 31, 1-71. (c) F. Dénès, A. Pérez-Luna and F. Chemla, Chem. Rev., 2010, $110,2366-2447$

14 G. Courtois and L. Miginiac, J. Organomet. Chem., 1974, 69, 1-44.

15 (a) M. Hayashi, S. Bachman, S. Hashimoto, C. C. Eichman and B. M. Stoltz, J. Am. Chem. Soc., 2016, 138, 8997-9000 (b) L. Zhao and X. Lu, Angew. Chem. Int. Ed. 2002, 41, 4343-4345. (c) B. Skillinghaug, C. Sköld, J. Rydfjord, F. Svensson, M. Behrends, J. Sävmarker, P. J. R. Sjöberg and M. Larhed, J. Org. Chem., 2014, 79, 12018-12032. (d) M. Xiong, X. Xie and Y. Liu, Org. Lett., 2017, 19, 3398-3401. (e) J. H. Kim and S.-G. Lee, Org. Lett., 2011, 13, 1350-1353.

16 S. Zhang, J. del Pozo, F. Romiti, Y. Mu, S. Torker and A. H. Hoveyda, Science, 2019, 364, 45-54.

17 See ESI for detail.

18 A. Boreux, K. Indukuri, F. Gagosz and O. Riant, ACS Catal., 2017, 7 8200-8204

19 A. Sawada, T. Fujihara and Y. Tsuji, Adv. Synth. Catal., 2018, 360, 2621-2625. 